\title{
Variation in Floral Phenological Synchronization in a Clonal Seed Orchard of Pinus tabuliformis in Northeast of China
}

\author{
By Wei Li ${ }^{1)}$, XIAORU WANG ${ }^{2)}$ and Yue $\mathrm{LI}^{\left.1{ }^{1)},{ }^{*}\right)}$
}

(Received 28 ${ }^{\text {th }}$ August 2011)

\begin{abstract}
Flowering phenology in an orchard is a crucial factor affecting the gene exchange among clones and consequently changing genetic composition of the seed crop. Pinus tabuliformis is now at the crucial period from first generation clonal seed orchards to advanced generation seed orchards in China. In this study, variation and stability in floral phenological synchronization of all the clones and possible mating pairs, in terms of an index of phenological overlap, were observed in a first generation clonal seed orchard which located in northeast of China. Results showed that significant variations occurred in the clones and mating pairs. This kind of variation was apparently related with temperature and humidity of the research site. With increasing age, levels of flowering synchronization were likely to rise in the clones and mating pairs. In general, the average flowering synchronization of male parents was slightly higher than that of female parents, female management in a seed orchard should be paied more attention. Flowering time was under strong genetic control and this genetic control was stronger in the female flowering process than of the males in terms of board sense heritability and year to year correlation analysis. Flowering synchronization of female parents was positively correlated between most years and can be a reliable reference for early and late predication in Pinus tabuliformis seed orchard during stage of initial seed harvest to stable seed production. According to their average levels of flowering synchronization, 49 clones in the first generation clonal seed orchard were divided into 11 different groups. Results of this paper provided the basic information for first generation seed orchard management and advanced seed orchard establishment of Pinus tabuliformis.
\end{abstract}

Key words: Pinus tabuliformis, first generation, clonal seed orchard, reproductive synchronization, phenological overlap index, genetic variation, clonal repeatibility, seed orchard management, advanced seed orchard establishment.

\section{Introduction}

A seed orchard is an intensively-managed plantation of specifically arranged trees for mass production of genetically improved seeds used for the establishment of new forests. Genetic quality of the seed crops in a seed orchard reach to its maximum should dependent on both breeding value of the founder parents and the basic bio-

\footnotetext{
1) National Engineering Laboratory for Forest Tree Breeding, College of Biological Sciences and Technology, Beijing Forestry University, Beijing 100083, P.R. China. E-Mail: bjfuliwei@bjfu.edu.cn

2) Department of Ecology and Environmental Science, Umeå University, Umeå SE-901 87, Sweden.

E-Mail: xiao-ru.wang@ibcas.ac.cn

*) Corresponding Author: Yue LI. Tel.: +86-10-62336064, Fax: +86-10-62337855. E-mail: liyue@bjfu.edu.cn
}

logical assumptions, such as floral phenological synchronization, equal production in male and female flowers, random mating, minimal self-pollination and isolation from non-orchard pollen sources, etc (ScHMIDTLING, 1983; AsKew, 1985; CoDESIDO et al., 2005). However, it is almost certain that these assumptions are virtually never satisfied. On the other hand, there are likely no limiting deviations from these assumptions, which lead to serious consequences in the seed crops of seed orchards (EL-KASSABY and REYNOLDS, 1990). Flowering phenology in an orchard is probably the single most important factor, since it affects exchange of the genes between clones and consequently changes the genetic composition of the seed lots derived from seed orchard (MATZIRIS, 1994; EL-KASSABY et al., 1988; ERICKSON and AdAMs, 1989; BurczyK and PRAT, 1997; ZAS et al., 2003). Many studies have shown that non-synchronous flowering is a serious problem in seed orchards of most coniferous species, such as Douglas-fir (COPES and SNIEZKo, 1991), Scots pine (SAVOlainen et al., 1993), Norway spruce (DANUSEVICIUs, 1987) and Picea mariana (O'REILlY and PARKER, 1982) etc.

Failure in synchronization of female flower receptivity and pollen shedding lead to an unbalanced contribution of clones, nonrandom cross-fertilization, or cause a high number of empty seeds as well as decrease the probability of background pollination and thus increase self-pollination (BoEs et al., 1991; WEBBER and PAINTER, 1996; BHUMIBHAMON, 1978). Furthermore, quantification of phenology synchronization of clones in a seed orchard is fundamental step for making decisions about orchard roguing, supplemental mass pollination and parent selection for advanced orchard establishment (EL-KASSABY and RITLAND, 1986). Several different mathematical models have been developed for quantifying the degree of flowering synchronization among all possible pairs and clones in the seed orchard. AsKew and BLUSH (1990) proposed an index of overlapping phenology $\left(P O_{i j}\right)$ which quantified the proportional symmetry of the female and male phenograms in terms of gamete contribution proportions. This index can facilitate measuring phonological overlap and provide an efficient tool for tracking and monitoring the stability of established orchards and has been successfully used in Pinus taeda (Askew and Blusg, 1990), Pinus pinaster (ZAs et al., 2003), Pinus tadiata (CoDEsido et al., 2005) and Pinus nigra (Alizoti et al., 2010) for reproductive phenological synchronization analysis.

Pinus tabuliformis, also referred to as Chinese pine, is an important native coniferous tree species in the north, northwest and parts of northeast of China (Li et al., 2011). It is naturally distributed in 14 provinces and 
autonomous regions in northern China, with a suitable habitat of 3 million $\mathrm{km}^{2}$ (ZHANG et al., 2004). Because of important ecological and economic status of Chinese pine as an indigenous coniferous tree species in northern China, project of genetic improvement and first generation clonal seed orchards was started in the 1970s in China (WANG et al., 1985). Up to now, basic aspects related to the genetic improvement of Chinese pine, such as biological features (ZHANG et al., 1995), grafting technologies, pollen distribution and exogenous pollen pollution etc have been comprehensively and systematically studied (Li et al., 2010). Currently, all first generation clonal Chinese pine seed orchards are 20 to 30 years old and the demand for improved seed for afforestation in China is increasing. Chinese pine seed orchards are at a critical stage for intensive management, such as pruning, roguing and parental selection for advanced seed orchard establishment. But current researches are inadequate in addressing the flowering synchronization among clones and mating pairs in this first generation Chinese pine seed orchard. Quantification of the phenology synchronization is the primary step in making decisions about orchard roguing, clonal pruning and advanced seed orchard establishment.

In our study, we determined the phenological variation in male and female flowering phenology in all the clones and possible mating pairs in terms of an index of phenological overlap and the extent to which environmental factors affecting flowering pnenology during the period from initial seed harvest to stable seed production in a first generation clonal seed orchard of Chinese pine. As well, we analyzed annually the correlation between average flowering synchronization of the clones as male, female and self-pollination and the broad sense heritability in male and female flowering synchronization. We also tried to divide clones in the seed orchard into different groups based on their average flowering synchronization level. Our objective was to quantify the stability and variation in floral phonological synchronization in a first generation clonal seed orchard of Chinese pine and thus provide fundamental information for orchard management and advanced future seed orchard establishment.

\section{Materials and Methods}

\section{Investigated seed orchard}

Our study was carried out in a first generation clonal Chinese pine seed orchard, located in Xingcheng City Liaoning Province, China $\left(40^{\circ} 44^{\prime} \mathrm{N}, 120^{\circ} 34^{\prime} \mathrm{E}, 100 \mathrm{~m}\right.$ above sea level). The orchard is composed of 49 clones in a $7 \mathrm{~m} \times 7 \mathrm{~m}$ fixed block design. Clones were grafted in 1974 using two-year old rootstock and planted in the field in 1975 (SHEN et al., 1985). Samples and investigations were carried out in the $9^{\text {th }}, 10^{\text {th }}, 13^{\text {th }}, 18^{\text {th }}$ and $21^{\text {st }}$ years after clone grafting in the seed orchard, spanning 13 years and covered the period from initial flowering to stable seed production.

\section{Climatic conditions}

The climate in the area of research is characterized by typical temperate and monsoonal climate with four clearly distinct seasons, dry and little rain in spring, hot and rainy in summer, cool and dry in autumn and cold and very dry in winter. The climatic data for the study period were obtained from the Meteorological Bureau of Xingcheng City.

The annual grand mean temperature is $8.6^{\circ} \mathrm{C}$. The colder month is January with a grand mean temperature down to minus $9.1^{\circ} \mathrm{C}$ and the warmest month is July with a grand mean temperature up to $24.0^{\circ} \mathrm{C}$. The area of the study receives on average annually $543.7 \mathrm{~mm}$ of precipitation; $14.8 \mathrm{~mm}$ in winter, $76.4 \mathrm{~mm}$ in spring, 353.6 in summer and 98.3 in fall.

\section{Methods}

We used a fixed sampling method in our investigation. Four ramets were selected randomly as sample plants from each clone. 10 female flowers were marked at the central part of sunny side of the selected plants. Most male flowers usually grow in the short middle branches on the shady side, so 10 male flower branches were marked at this location. As much as possible the positions of the marked flowers were kept consistent (LI and SHEN, 1994).

During the years of observation, the marked flowers were monitored and recorded at a fixed time, such as each noon, during flowering stage of the clones. We distinguished four female and four male stages. The female stages were described by MATZIRIS (1994) and CoDESIDO (2005) as follows: stage 1, the female bud is increasing in size, becomes cylindrical, but is still completely covered by the bud scales; stage 2, the apex of the enlarged cylindrical bud is opened and the first ovuliferous scales appear; stage 3 , the scales of the female conelet are gradually separated and almost form right angles with the axis of the conelet, and stage 4 , the ovuliferous scales increase in size and thickness so that the strobili are no longer receptive.

The male stages were described as follows by CoDESIDo and Merlo (2001) and Codesido et al. (2005): stage 1 , the round brown strobili are covered by bud scales; stage 2, the male strobili burst through the bud scales and elongate; stage 3 , the yellow strobili start shedding their pollen and stage 4, end of pollen shedding.

An index of phenological overlap was calculated following AsKew and BLUSH (1990). The index was estimated for each possible pair of mating clones, for self-pollination between ramets of the same clone, and for individual clones acting as males and/or females.

$$
\begin{aligned}
P O_{i j} & =\sum_{k=1}^{n} \min \left(M_{k i}, P_{k j}\right) / \sum_{k=1}^{n} \max \left(M_{k i}, P_{k j}\right) \\
P O_{i .} & =\sum_{j=1}^{n} \frac{P O_{i j}}{t-1} \\
P O_{. j} & =\sum_{i=1}^{n} \frac{P O_{i j}}{t-1}
\end{aligned}
$$

Where: $P O_{i j}$ is the flowering synchronization index between the $i$ th and the $j$ th clones; If $i=j, P O_{i j}$ is the flowering synchronization index between the ramets of the same clone; $P O_{i}$. and $P O_{. j}$ are the average synchro- 
nization index of the $i$ th and $j$ th clones as male and female parent respectively; $M_{k i}$ is the ratio of shedding male flower of the $i$ th clone at day $k$ in the seed orchard; $P_{k j}$ is the ratio of the receptive female flower of the $j$ th clone at day $k$ in the seed orchard; $n$ is the lasting flowering days from the earliest to the last in the clones of $i$ and $j$ as female and male.

To better understand what extent the flowering synchronization was controlled by genetics, broad sense heritability $\left(h^{2}{ }_{c}=\right.$ clonal repeatibility) were calculated using the following formula.

$$
h_{c}^{2}=\sigma_{c}^{2} /\left(\sigma_{c}^{2}+\sigma_{e}^{2} / b\right)
$$

Where: $h^{2}$ is the repeatability of flowering synchronization, $\sigma_{c}^{2}$ is the estimated variance of clone, and $\sigma_{e}^{2}$ is the estimated variance among ramets within clone, $b$ is the harmonic mean of number of ramets per clone.

\section{Results}

\section{Variation in flowering synchronization of clones}

Initial flowering year and flowering phenology of the clones in the seed orchard were determined. The overall statistics of overlapping phenology index of female receptivity and pollen shedding and mean value, coefficient of variation (CV) and correlation coefficent are shown in Table 1.

At early years of seed production in the seed orchard $\left(9^{\text {th }}, 10^{\text {th }}\right.$ and $13^{\text {th }}$ year $)$, a large part of the clones did not bear male or female flowers. Not until 18 years after the establishment of the seed orchard did most of the clones start to contribute to gamete composition. In the five years of study, coefficient of variation of annual male flowering synchronization varied from $12 \%$ to $38 \%$, with average $\mathrm{CV}$ of male flowering synchronization during these five years reaching $9.5 \%$. In female flowering synchronization, the CV varied annually from $9 \%$ to $24 \%$,

Table 1. - Average flowering synchronization in Pinus tabuliformis seed orchard.

\begin{tabular}{|c|c|c|c|c|c|c|c|c|c|c|}
\hline $\mathrm{Agc}$ & \multicolumn{2}{|c|}{$9 a$} & \multicolumn{2}{|c|}{ T0a } & \multicolumn{2}{|c|}{$13 a$} & \multicolumn{2}{|c|}{$18 \mathrm{a}$} & \multicolumn{2}{|c|}{$21 a$} \\
\hline Clone & 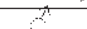 & 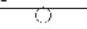 & 4 & $\%$ & . & & & & & 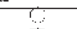 \\
\hline 1 & - & $0 . \overline{172}$ & 0.264 & $0 . \overline{158}$ & 0.176 & $0 . \overline{20} 3$ & 0.560 & 0.666 & 0.110 & $0 . \overline{142}$ \\
\hline 2 & 0.316 & 0.153 & 0.098 & 0.168 & 0.167 & 0.223 & 0.635 & 0.659 & 0.146 & 0.157 \\
\hline 3 & -- & 0.147 & 0.207 & 0.173 & 0.229 & 0.213 & 0.553 & 0.679 & 0.188 & 0.146 \\
\hline 4 & -- & 0.169 & - & 0.183 & $\begin{array}{c}0 \\
-1\end{array}$ & 0.172 & 0.536 & 0.184 & 0.207 & 0.127 \\
\hline 5 & 0.320 & -- & 0.235 & -- & 0.194 & -- & 0.510 & & 0.213 & 0.128 \\
\hline 6 & - & 0.196 & 0.157 & 0.176 & -- & 0.223 & 0.526 & 0.647 & 0.230 & 0.129 \\
\hline 7 & -- & 0.073 & $\begin{array}{c}-1 \\
-1\end{array}$ & 0.101 & 0.241 & 0.225 & 0.462 & 0.630 & 0.201 & 0.118 \\
\hline 8 & -- & 0.118 & 0.277 & 0.158 & 0.200 & 0.211 & 0.510 & 0.636 & 0.143 & 0.158 \\
\hline 9 & 0.198 & 0.116 & 0.169 & 0.101 & 0.160 & 0.183 & 0.587 & 0.192 & 0.058 & 0.138 \\
\hline 10 & 0.211 & -- & 0.248 & 0.162 & - & - & 0.473 & 0.616 & (0. 145 & 0.117 \\
\hline 11 & -- & 0.145 & -- & 0.243 & -- & 0.243 & 0.573 & 0.546 & 0.074 & 0.188 \\
\hline 12 & -- & 0.101 & 0.246 & 0.106 & 0.213 & 0.181 & .475 & 0.651 & 0.076 & 0.142 \\
\hline $1 \overline{3}$ & -- & 0.167 & 0,287 & 0.188 & 0.178 & 0.212 & 0.458 & 0.619 & 0.195 & 0.110 \\
\hline 14 & -- & 0.130 & -- & 0.155 & -- & 0.225 & 0.342 & 0.685 & 0.109 & 0.137 \\
\hline 15 & -- & 0.153 & 0.127 & 0.202 & 0.167 & 0.181 & 0.618 & 0.436 & 0.206 & 0.134 \\
\hline 16 & 0.278 & 0.182 & 0330 & 0.007 & 0.210 & 0.217 & 588 & 0680 & 0.123 & (1) 140 \\
\hline 17 & 0.217 & 0.184 & 0.325 & 0.188 & 0.348 & 0.203 & 40 & 0.370 & 0.097 & 0.134 \\
\hline 18 & - & 0.183 & - & 0212 & 0537 & 0.218 & 40 & 0.532 & 0.100 & 0169 \\
\hline 19 & 0.301 & 0.087 & 0.204 & 0.151 & 0.160 & 0.192 & .563 & 0.610 & (). 138 & (1) 138 \\
\hline 20 & 0.154 & 0.188 & -- & 0.214 & -- & -- & 0.563 & 0.449 & 0.083 & 0.193 \\
\hline 21 & 0.234 & -- & 0.224 & 0.143 & 0.289 & -- & 0.511 & 0.655 & (0.2] & 0.139 \\
\hline 22 & -- & -- & -- & 0.118 & - & 0.207 & 497 & 0.574 & 0.091 & 0.116 \\
\hline 23 & -- & 0134 & -- & 0110 & -- & 0202 & 69 & 0693 & 0183 & 0090 \\
\hline 24 & -- & 0.121 & 0.295 & 0.172 & 0.248 & 0.191 & 25 & 0.5 & 136 & 0.163 \\
\hline 25 & -- & 0.145 & -- & 0.176 & 0.205 & 0.219 & 556 & 0.278 & 0.182 & 0.155 \\
\hline 26 & 0.294 & -- & 0.368 & 0.162 & 0.266 & $\begin{array}{c}0.21 \\
--\end{array}$ & 0.549 & 0.646 & 0.051 & (1.189 \\
\hline 27 & 0.292 & 0.174 & 0.136 & 0.191 & 0.285 & -- & 0.549 & 0.633 & 0.036 & 0203 \\
\hline 28 & 0.094 & 0.113 & - & 0.179 & 0.240 & 0.198 & 0.568 & - & 0.082 & 0. 162 \\
\hline 29 & - & 0124 & 0421 & 0170 & 0216 & 0195 & 06 & 0,640 & 197 & 0131 \\
\hline 30 & 0.315 & 0.176 & 0.278 & 0199 & 0226 & 0220 & & 0.5 & 0.216 & 0.166 \\
\hline 31 & -- & 0.157 & -- & 0.182 & -- & 0.211 & 0.597 & 0.557 & 0.163 & 0.141 \\
\hline 32 & -- & 0146 & 0340 & 0182 & 0212 & 0178 & 0555 & 0624 & 0201 & 0126 \\
\hline 33 & 0.328 & 0.167 & 0247 & 0207 & 0200 & 0204 & 0601 & 0514 & 0.186 & 0123 \\
\hline 34 & - & 0.136 & 0.194 & 0.203 & 0.248 & 0.183 & & 0.346 & & 170 \\
\hline 35 & 0.346 & 0096 & 0.172 & 0.155 & 0239 & 0.190 & 53 & 0.571 & 0.090 & 0.179 \\
\hline 36 & -- & 0.125 & 0.354 & 0.197 & -- & 0.198 & & 0.6 & 0.136 & 0.134 \\
\hline 37 & 0.345 & 0.154 & 0.163 & 0.218 & 0.176 & 0.169 & 0.649 & 0.5 & 0.039 & 0.210 \\
\hline 38 & -- & 0.147 & 0.452 & 0.202 & 0.186 & 0.196 & 0.518 & 0.499 & 0.186 & 0.118 \\
\hline 3 & -- & 0.212 & -- & 0.219 & 0.263 & 0.210 & & & & 0.194 \\
\hline 40 & -- & -- & -- & 0.1 & 0.259 & -- & & 0.6 & 38 & 0.137 \\
\hline 41 & -- & 0.157 & 0.217 & 0.210 & -- & 0.215 & & 0.4 & 0.142 & 0.129 \\
\hline 42 & -- & 0.087 & -- & 0. 154 & 0.197 & 0.167 & il & 0.562 & (1. 190 & 0.116 \\
\hline 43 & 0.311 & 0.107 & 0.100 & 0.209 & 0.166 & 0.195 & 0.635 & 0.605 & 0.081 & 0.162 \\
\hline 4 & & -- & -- & (1) 182 & () 224 & -_ & & 0.621 & 0219 & (1) 143 \\
\hline 45 & 0.385 & 0.065 & 0.261 & 0.153 & 0.195 & 0.165 & & 0.597 & 0.175 & 0.141 \\
\hline 46 & 0.196 & 0.170 & 0.269 & 0.217 & $0.2] 7$ & 0.210 & & 0.568 & (1. 121 & 0. 145 \\
\hline 47 & (1) 361 & 0.163 & 0383 & 0.207 & 0.242 & 0.183 & 0.5 & 0.578 & 0.216 & () 130 \\
\hline 48 & 0.401 & 0.158 & 0.285 & 0.155 & $0.25 \overline{3}$ & 0.206 & 0.467 & 0.653 & 0.150 & 0.131 \\
\hline 50 & $=$ & - & -- & 0.073 & 0.191 & 0.192 & 0.648 & 0.632 & 0.198 & (1) 153 \\
\hline CVI\% & 29 & 24 & 35 & 21 & 16 & 9 & 12 & 22 & 38 & 17 \\
\hline Vean & 0.279 & 0.144 & 0.253 & 0.174 & 0.217 & 0.201 & 0.540 & 0.563 & 0.145 & 0.146 \\
\hline $\begin{array}{l}\text { Correlatio } \\
\text { coefficen }\end{array}$ & & & & & & & & $91 *$ & & $0 * *$ \\
\hline
\end{tabular}

Note: --means not flowering in that year; * represents significance at 0.05 level; ** represents significance at 0.01 level; the same comments apply to the following tables. 
with an average of $16.9 \%$. Correlation coefficents between flowering synchronization of female receptivity and pollen shedding within a clone were mostly negative except for the $10^{\text {th }}$ year. In the $21^{\text {st }}$ year, the correlation coefficents reached to statistically significant with a value of -0.6110 (Table 1 ).

Flowering duration varied considerably among years. This kind of variation was apparently related with temperature and humidity of the research site. In the $9^{\text {th }}$ year, the receptive periods in the entire seed orchard were 21 and 15 days for the years $9^{\text {th }}$ and $10^{\text {th }}$, respectively; and the pollen shedding periods were 10 and 7 days in $9^{\text {th }}$ and $10^{\text {th }}$, respectively. Maximum female receptive was earlier than the peak of pollen shedding by 9 days in the $9^{\text {th }}$ year and by 5 days in the $10^{\text {th }}$ year. Meteorological data showed that during the flowering days of the $10^{\text {th }}$ year obviously higher temperature and lower humidity occurred compared with other years.
This high temperature and low humidity accelerated flowering process (Figure 1 and Figure 2).

Although the initiation, cessation and duration of female receptivity and pollen shedding varied considerably among years but the variation in accumulated temperature in the growing degree-days was comparatively low. Clone 9 and clone 29 have typical of early and late flowering patterns, respectively. For clone 9, the accumulated temperature of $\geq 5^{\circ} \mathrm{C}$ until the day of flowering initiation were $180.0,173.6$ and 190.0 in the $9^{\text {th }}, 10^{\text {th }}$ and $13^{\text {th }}$ year, respectively. For clone 29 , the accumulated temperature of $\geq 5^{\circ} \mathrm{C}$ until the day of flowering initiation were $284.3,287.3$ and 285.0 in the $9^{\text {th }}, 10^{\text {th }}$ and $13^{\text {th }}$ year, respectively. The average of accumulated temperature of $\geq 5{ }^{\circ} \mathrm{C}$ until the day of flowering initiation in the seed orchard were $257.0,254.0$ and 259.1 in the $9^{\text {th }}, 10^{\text {th }}$ and $13^{\text {th }}$ year, respectively. In general accumulated temperature of $\geq 5^{\circ} \mathrm{C}$ are more stable than that of $10^{\circ} \mathrm{C}$ for

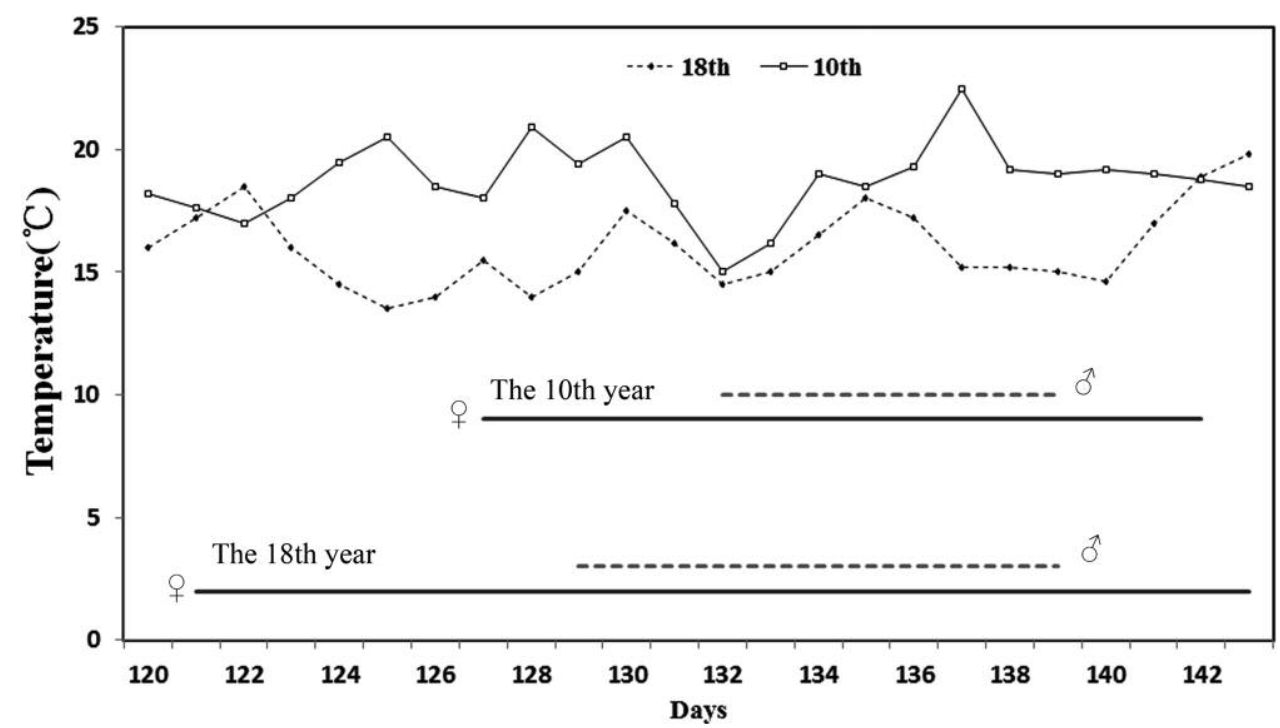

Figure 1. - Dates of female and male initiation, cessation and duration (continuous bars and broken bars) and their relation with average temperature during the flowering period in Chinese pine seed orchard.

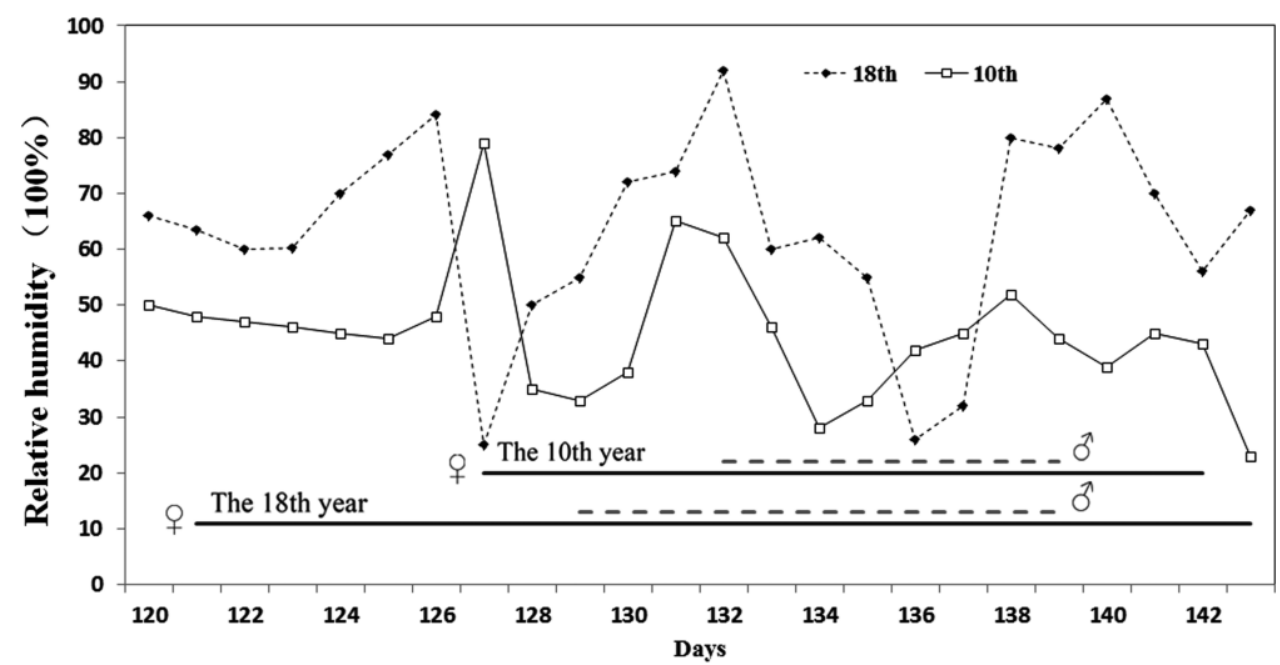

Figure 2. - Dates of female and male initiation, cessation and duration and their relation with relative humidity during the flowering period in Chinese pine seed orchard. 


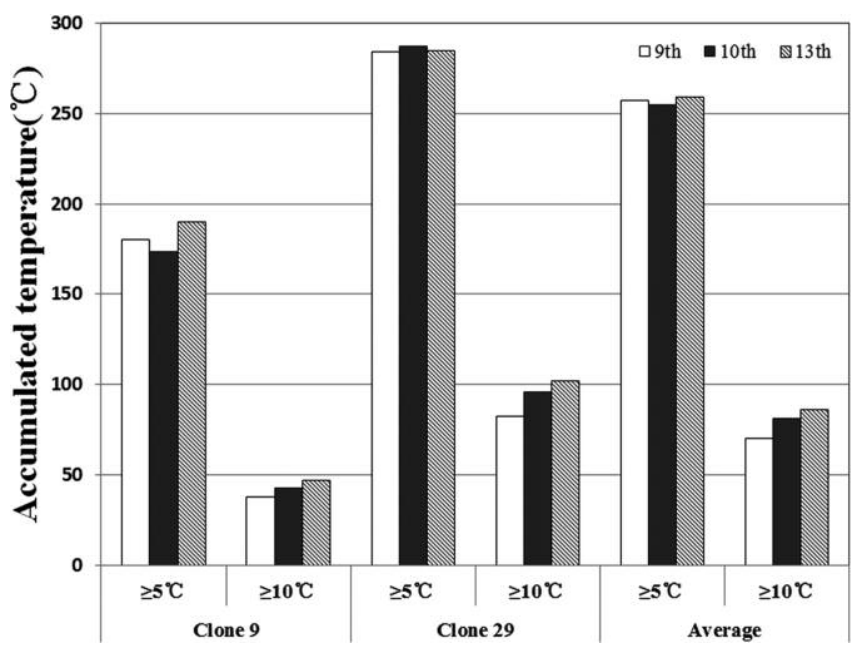

Figure 3. - The accumulated temperature of $\geq 5^{\circ} \mathrm{C}$ and $\geq 10^{\circ} \mathrm{C}$ until the day of flowering initiation in Chinese pine seed orchard.

flowering initiation of Chinese pine (Figure 3). For clone 9 , the cumulative growing degree-days of $\geq 5^{\circ} \mathrm{C}$ until flowering initiation were 35,29 and 33 in the $9^{\text {th }}, 10^{\text {th }}$ and $13^{\text {th }}$ year, respectively. For clone 29 , it were 47,41 and 41 in the $9^{\text {th }}, 10^{\text {th }}$ and $13^{\text {th }}$ year, respectively. The average of the $\geq 5^{\circ} \mathrm{C}$ cumulative growing degree-days until flowering initiation in the seed orchard were 44, 38 and 39 in the $9^{\text {th }}, 10^{\text {th }}$ and $13^{\text {th }}$ year, respectively (Figure 4).

The year to year variation in the flowering patterns can be observed in graph of overall phenology synchronicity (Figure 5 and Figure 6). In general, flowering synchronization increased when the seed orchard changed from its initial seed production to stable seed production. The yearly female flowering synchronizations ranged from 0.144 to 0.563 , with a mean value of 0.249 . Except for the $18^{\text {th }}$ year, in which the synchronization index reached 0.563 (rainy weather delayed the flowering period), index observed for the other years remained largely under 0.2. Male flowering synchronizations ranged from 0.145 to 0.279 and were usually more than 0.2 , except for the $21^{\text {st }}$ year. Synchronization

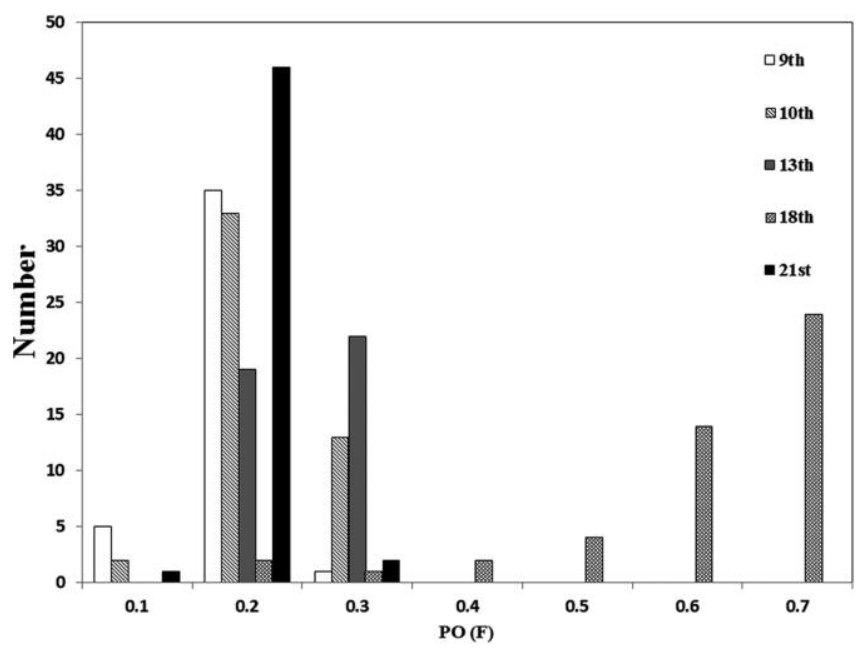

Figure 5. - Frequency histograms for PO indices (Female).

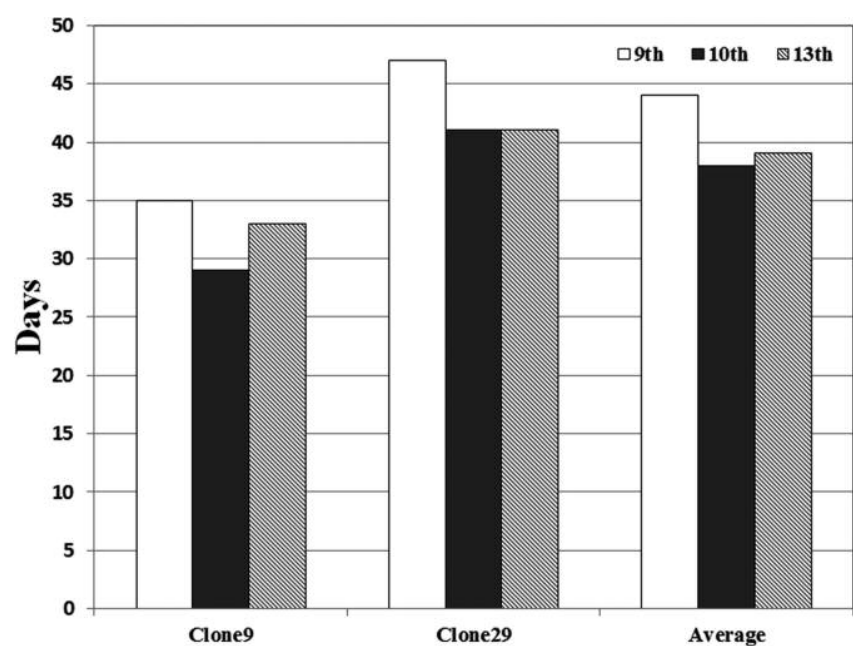

Figure 4. - The cumulative growing degree-days of $\geq 5^{\circ} \mathrm{C}$ until flowering initiation in clone 9 , clone 29 and the average in Chinese pine seed orchard.

in pollen shedding was slightly higher than that of female receptivity during juvenile stage, but reached to nearly equal after the seed orchard entering into mature stage (Table 1).

The broad sense heritability values based on clone means of male and female flowering synchronization were very high among the five years, with mean values of 0.83 and 0.72 for female and male flowering synchronization, respectively.

\section{Variation in flowering synchronization of mating pairs}

Significant variation appeared in the flowering synchronization of all the possible mating pairs. For example, in the $18^{\text {th }}$ year, flowering synchronizations in mating pares between clone 18 and other clones in the seed orchard were apparently higher than that of clone 13 . With all possible mating pairs in the seed orchard, flowering synchronizations of the same clones as male parent and female parent also changed significantly. For example, synchronization between pollen shedding of clone 18 and female receptivity of clone 20 reached 0.9 , whereas synchronization between pollen shedding of

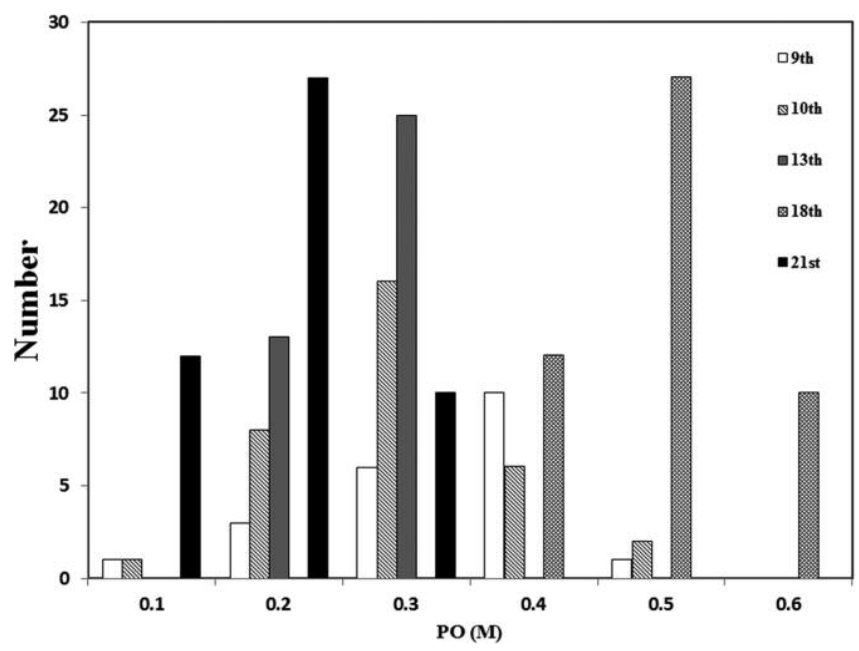

Figure 6. - Frequency histograms for PO indices (Male). 


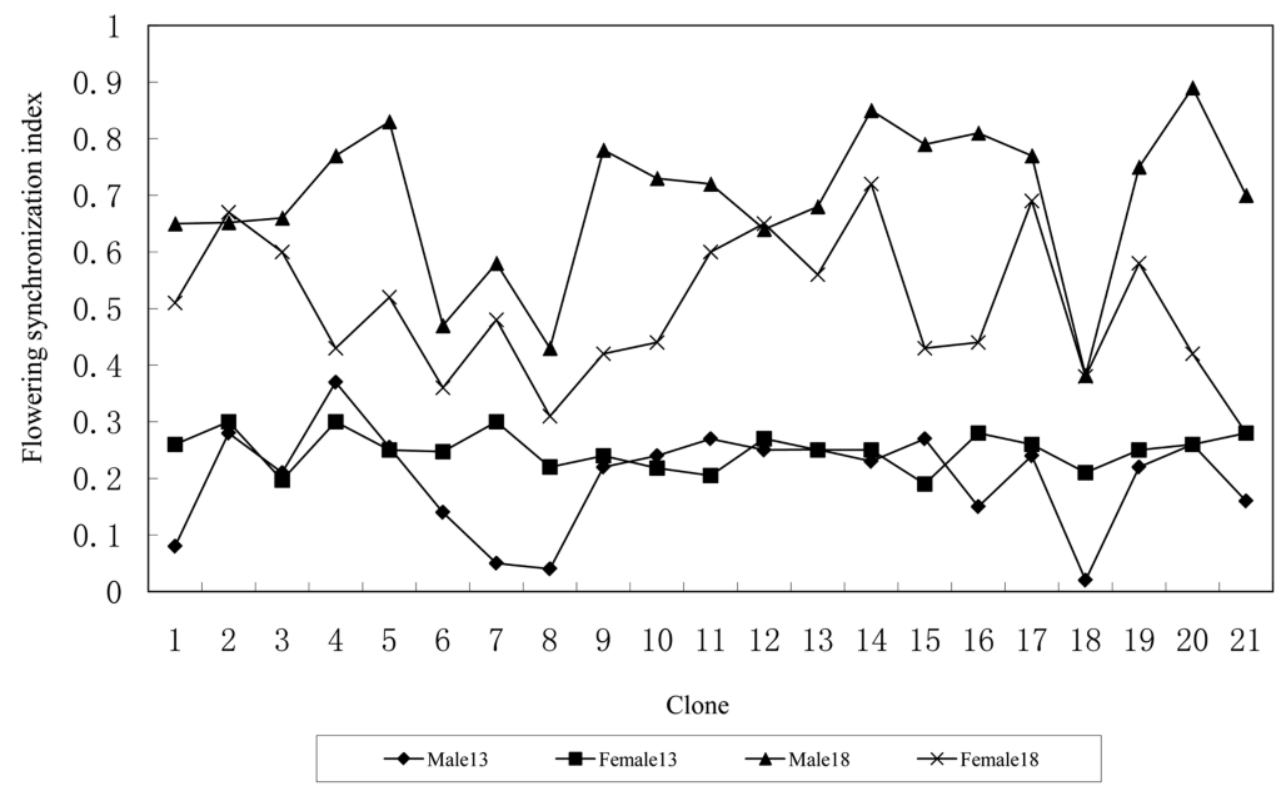

Figure 7. - Flowering synchronizations of mating pairs in Xingcheng Pinus tabuliformis seed orchard.

Note: Male 13 means clone 13 served as male parent; Female 13 means clone 13 served as female; similar comments apply to other clones.

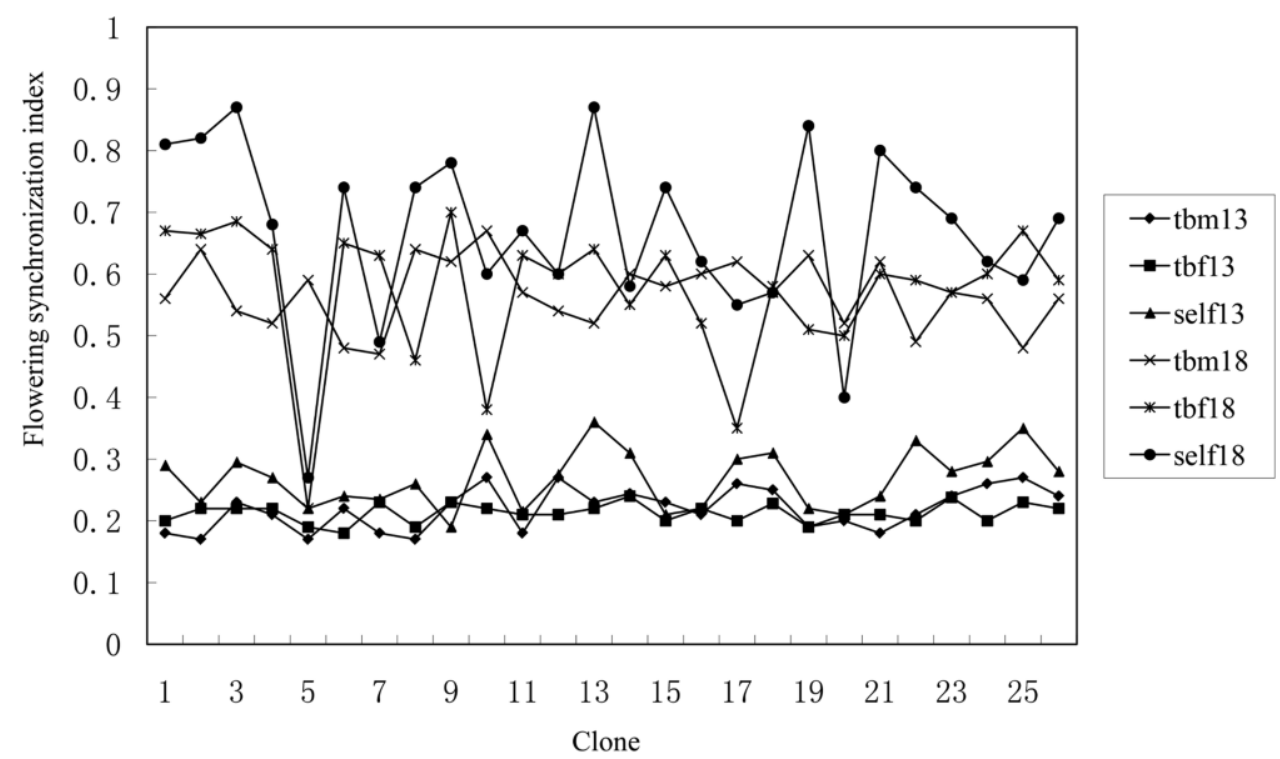

Figure 8. - Flowering synchronizations of clones as male and female parent and self-pollination in Xingcheng Pinus tabuliformis seed orchard.

Note: tbm 13 means one clone served as male parent in $13^{\text {th }}$ year after seed orchard establishment; tbf 13 means one clone served as female parent in $13^{\text {th }}$ year after seed orchard establishment; self 13 means self-pollination in $13^{\text {th }}$ year after seed orchard establishment; similar comments apply to other clones.

clone 18 and flower receptivity of clone 8 only reached 0.42 and self-pollination synchronization of clone 18 was 0.38. In all possible mating pairs with clone 13 , the flowering synchronizations were relatively stable compared with other clones. Results from over the five years observations indicated that this apparent variation in flowering synchronizations of different mating pairs in Chinese pine seed orchards was quite common. Based on this information, we can conclude that clone selection and clone allocation are the most important factors to be considered before an advanced Chinese pine seed orchard establishment (Figure 7).

Self-pollination was another important factor affecting genetic quality of the seed crop in the seed orchard. It can be seen that flowering synchronizations of self-pollination in about $80 \%$ clones of the seed orchard were always higher than the average flowering synchronization when it served as male and female parents at juvenile stage (the $13^{\text {th }}$ year) and stable seed production stage (the $18^{\text {th }}$ year). Only in about $20 \%$ clones, flower- 
Table 2. - Correlation analysis of the flowering synchronization between the observed years in Pinus tabuliformis seed orchard.

\begin{tabular}{|c|c|c|c|c|c|c|c|c|c|}
\hline & $113 \mathrm{M}^{9}$ & ]'B & IBM 10 & 'I'BS: 10 & l13M13 & THB 13 & T13M18 & T'PJ:18 & Т'BМ21 \\
\hline IBम99 & -0.177 & & & & & & & & \\
\hline ТВMI0 & 0.007 & 0.1572 & & & & & & & \\
\hline TBF 10 & -0.031 & $0.500 * *$ & 0.011 & & & & & & \\
\hline THM 13 & -0.120 & 0.267 & $0.422^{*}$ & 0.052 & & & & & \\
\hline TBF 13 & 0.037 & $0.346^{*}$ & 0.069 & 0.103 & 0.099 & & & & \\
\hline TBM18 & -0.101 & 0.108 & $-0.495^{*}$ & 0.357 & -0.190 & 0.038 & & & \\
\hline TBE 18 & 0.310 & -0.16 & 0.176 & -0.112 & 0.069 & 0.339 & $-0.439^{*}$ & & \\
\hline [13M2 1 & 0.297 & -0.053 & $0.354^{*}$ & -0.047 & -0.075 & -0.071 & -0.096 & 0.075 & \\
\hline ТВЕ2 I & 0.113 & 0.239 & -0.051 & $0.368^{* *}$ & -0.099 & $0.939 \%$ & $0.339^{*}$ & $-0.387^{* *}$ & -0.056 \\
\hline
\end{tabular}

Note: TBM9 means clonal flowering synchronization index as male in the $9^{\text {th }}$ year after clone grafting in the seed orchard; TBF9 means clonal flowering synchronization index as female in the $9^{\text {th }}$ year after clone grafting in the seed orchard; similar comments apply to other clones.

Table 3. - Clone classification by level of the average flowering synchronization in Pinus tabuliformis seed orchard.

\begin{tabular}{|c|c|c|c|c|c|c|c|c|c|c|c|c|c|c|c|c|c|c|}
\hline No. & Clone & $\mathrm{PO}$ index & \multicolumn{7}{|c|}{ Duncan group } & No. & Clone & $P^{3} O$ index & \multicolumn{6}{|c|}{ Duncan group } \\
\hline 1 & 15 & 0.061550 & & & & A & & & & 26 & 29 & 0.015850 & $\mathrm{~F}$ & I & ] I & $\mathrm{K}$ & & \\
\hline 2 & 31 & 0.045325 & & & & B & & & & 27 & 21 & 0.015375 & & I & $\mathrm{H}$ & K & J & $G_{\mathrm{S}}$ \\
\hline 3 & 32 & 0.042475 & & C & & $\mathrm{B}$ & & & & $2 x$ & 27 & 0.015150 & & I & JI & K & J & $\mathrm{G}$ \\
\hline 4 & 1 & 0.041425 & & C & & B & $\mathrm{D}$ & & & 29 & 5 & 0.015050 & & I & $\mathrm{H}$ & K & J & G \\
\hline 5 & 16 & 0.037550 & & C & $\Gamma$ & $B$ & $\mathrm{D}$ & & & 30 & 19 & 0.015025 & & I & II & $\mathrm{k}$ & J & $\mathrm{G}$ \\
\hline 6 & 24 & 0.036250 & & C & $\mathrm{L}$ & $\mathrm{B}$ & $\mathrm{D}$ & & & $3]$ & 34 & 0.014675 & & I & ] & $\mathrm{K}$ & j & $\mathrm{G}$ \\
\hline 7 & 17 & 0.031275 & $\mathrm{~F}$ & $\mathrm{C}$ & $\mathrm{E}$ & B & D) & & & 32 & 7 & 0.014425 & & I & $\mathrm{H}$ & $\mathrm{K}$ & j & \\
\hline 8 & 3 & 0.030600 & $\mathrm{~F}$ & C & $\Gamma$ & $\mathrm{B}$ & D & & $\mathrm{G}$ & 33 & 12 & 0.013675 & & I & II & $\mathrm{K}$ & J & \\
\hline 9 & 30 & 0.029225 & $\mathrm{~F}$ & C & E & $\mathrm{H}$ & D & & G & 34 & 33 & 0.013525 & & I & $\mathrm{H}$ & K & j & \\
\hline 10 & 35 & 0.027050 & $\mathrm{~F}$ & l & $\mathrm{E}$ & $\mathrm{H}$ & I) & & $\mathrm{G}$ & 35 & 18 & 0.013450 & & I & $\mathrm{H}$ & 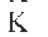 & J & \\
\hline 11 & 26 & 0.026125 & $\mathrm{~F}$ & I & $\mathrm{F}$. & II & & & $\mathrm{G}$ & 36 & 39 & 0.013150 & & I & II & $\mathrm{K}$ & J & \\
\hline 12 & 45 & 0.024875 & $\mathrm{~F}$ & l & L' & $\mathrm{H}$ & & J & $\mathrm{G}$ & 37 & 50 & 0.012875 & & I & & $\mathrm{k}$ & j & \\
\hline 13 & 46 & 0.024600 & $\mathrm{~F}$ & l & L: & $\mathrm{H}$ & & J & $\mathrm{G}$ & 38 & 40 & 0.012775 & & I & & $k$ & J & \\
\hline 14 & 25 & 0.024075 & F & I & $\mathrm{F}$ & II & K & J & $\mathrm{G}$ & 39 & 28 & 0.012225 & & I & & $\mathrm{K}$ & J & \\
\hline 15 & 2 & 0.023275 & $\mathrm{~F}$ & i & L: & $\mathrm{H}$ & $\mathrm{K}$ & J & $\mathrm{G}$ & 40 & 9 & 0.012050 & & I & & $\mathrm{K}$ & J & \\
\hline 16 & 13 & 0.020800 & $\mathrm{H}$ & 1 & & $\mathrm{H}$ & $\mathrm{K}$ & J & G & 41 & 6 & 0.011900 & & I & & K & J & \\
\hline 17 & 11 & 0.019700 & $\mathrm{~F}$ & l & & II & $\mathrm{K}$ & J & (i & 42 & 41 & 0.011750 & & I & & $\mathrm{K}$ & J & \\
\hline 18 & 38 & 0.017300 & $\mathrm{~F}$ & 1 & & $\mathrm{H}$ & $\mathrm{K}$ & J & G & 43 & 42 & 0.011350 & & I & & K & J & \\
\hline 19 & 37 & 0.016825 & $\mathrm{H}$ & 1 & & $\mathrm{H}$ & $\mathrm{K}$ & J & $\mathrm{G}$ & 44 & 44 & 0.010900 & & I & & $\mathrm{K}$ & j & \\
\hline 20 & 47 & 0.016725 & $\mathrm{~F}$ & ] & & II & $\mathrm{K}$ & J & G & 45 & 10 & 0.010800 & & I & & $\mathrm{K}$ & J & \\
\hline 21 & 4 & 0.016625 & $\mathrm{~F}$ & 1 & & $\mathrm{H}$ & $\mathrm{K}$ & J & $\mathrm{G}$ & 46 & 20 & 0.010700 & & I & & $\mathrm{K}$ & j & \\
\hline 22 & $4 \hat{i}$ & 0.016525 & $F$ & T & & II & $\mathrm{K}$ & J & G & 47 & 23 & 0.009200 & & & & $\mathrm{~K}$ & J & \\
\hline 23 & 36 & 0.016275 & $\mathrm{~F}$ & i & & II & $\mathrm{K}$ & J & G & 48 & 14 & 0.008850 & & & & K & J & \\
\hline 24 & 48 & 0.016150 & F & $\mathrm{T}$ & & $\mathrm{H}$ & $\mathrm{K}$ & J & G & 49 & 22 & 0.007900 & & & & K & & \\
\hline 25 & 8 & 0.015950 & $\mathrm{~F}$ & j & & II & $k$ & J & (; & & & & & & & & & \\
\hline
\end{tabular}

Note: PO means phenological overlap; same letters in Duncan's group column means same group divided by flowering synchronization level.

ing synchronizations of self-pollination lower than the clonal average flowering synchronization. This results showed that most of the clones have a higher possibility of self-pollination than the average level of out-crossing, which should be concerned when parents selected for an advanced Chinese pine seed orchard establishment (Figure 8).

Correlation coefficents between male and female flowering synchronization were negative in four of the five observed years and reached to statistically significant level in the $18^{\text {th }}$ and $21^{\text {st }}$ year at 0.05 and 0.01 level, respectively. This indicated that flowering synchronization between different genders within one clone always showed an opposite trend. It was also an important factor to be considered for an advanced Chinese pine seed orchard establishment and clone management in a first generation seed orchard (Table 1).

\section{Annual variation in flowering synchronization}

Correlation analysis showed that significant positive correlation existed in male flower synchronizations between the $10^{\text {th }}$ year and that of the $13^{\text {th }}$ and $21^{\text {st }}$ year. Significant negative correlation occurred in male flowering synchronization between the $10^{\text {th }}$ year and the $18^{\text {th }}$ year, while no significant correlation appeared among the rest years. Conversely, indexes of female flowering synchronization were positively correlated among most of the observed years (except for the $18^{\text {th }}$ year) and some correlations reached to statistically significant level. Index of self-pollination synchronization in the $10^{\text {th }}$ year was significantly correlated with that of the $13^{\text {th }}$ year, while it did not show any significant correlation in other years. Self-pollination synchronizations were positively correlated with male flower synchronization and reached a level of statistical significance in the $10^{\text {th }}$ and 
$13^{\text {th }}$ year. Results of study show that reproductive synchronizations of the clones have a certain relative stability and thus could be used as an indication for early and late predication in Chinese pine seed orchard (Table 2, Figure 8).

\section{Clone classification by flowering synchronization}

Results from ANOVA showed that variation in average flowering synchronization of the clones as both male and female parents reached to statistically significant at 0.01 level. The coefficient of variation reached $57.65 \%$ in average flowering synchronization of the female parents. Based on this information, we can conclude that the realized genetic gain of the seed lots from this seed orchard can be greatly improved by clone selection and optimization in terms of flowering synchronization. Multiple comparisons with Duncan's method showed that the 49 clones can be divided into 11 groups according to their average levels of flowering synchronization in which group A included the minimum membership of clone 15 , while group $\mathrm{J}$ has the maximum members of 37 clones (Table 3). So in seed orchard of Chinese pine, orchard management and advanced seed orchard establishment should consider average flowering synchronizations of the selected clones for genetic improvement.

\section{Discussion}

Floral synchronization of pollen shedding and female receptivity is of major importance in seed orchards. First generation seed orchard always has more clones or families than the improved or advanced seed orchard, thus significant variation in phenology of flowering has been found in nearly all this kind of seed orchard (SARVAS, 1962, 1968; El-Kassaby and ReYNOLDS, 1990; MATZIRIS, 1993). It has previously been reported for Norway spruce (ERIKSSON et al., 1973), for Douglas-fir (ELKASSABY et al., 1984) and Radiata pine (GRIFFIN, 1984), and others. In our study, variation among clones in this first generation clonal seed orchard of Chinese pine was also statistically significant during stage of initial seed harvest to stable seed production. In the early years, $30 \%$ clones in the orchard were not flowering and until about 18 years later, all the clones entered into the stage of stable seed production. Different from most of other pines which male and female flowering phenology started at about the same time (BLUsH et al., 1993), female flowering in Chinese pine started about 3 to 7 days before male flowering.

Variation in clonal floral phenology resulted in changes in flowering synchronization of the clones served as male and female parents. In the years of observation, clonal flowering synchronizations were statistically different within and among the years which reflected variations in pollen cloud composition in the seed orchard, ultimately affecting the annual genetic contribution to seed crops. From this point of view, conditions could hardly be satisfied for genetic gain of seed crops reaching the maximum level. In general, with increasing age of the seed orchard from early seed harvest to stable seed production, levels of floral phenologi- cal synchronization of the clones show a corporately rising trend. But the flowering process was easily affected by environmental factors during the flowering seasons. In the area of research, there are seldom rainfalls during flowering days of spring and the weather condition are nearly stable during the study years. But in the $18^{\text {th }}$ year, rainfall occurred during flowering stage. Pollen shedding was interrupted and prolonged its duration, thus improving the value of flowering synchronization. It has been reported that rainfall interferes with the phenology process mainly through changing the relative humidity and temperature conditions (COPES and SNIEZKO, 1991). In our studies, the average flowering synchronization of male parents was higher in general than that of female parents as similar results were found in Cunninghamia lanceolata (Lamb.) Hook (CHEN et al., 1995). This indicated that clones as female parents were of greater importance than male parents and it was the major genetic factor affecting levels of genetic gain of the seed crops in Chinese pine seed orchard. Fundamental decisions should be affected by clones serving as female parent or male parent in orchard management, such as roguing and advanced seed orchard establishment.

Floral phenology demonstrated comparatively stability during five years of study in term of the index of clonal flowering synchronization in the seed orchard. Clones that flowered early in one year usually did so in other years as well; late flowering clones were also consistently late in flowering. Similar results have been also reported for several other conifers such as Radiata pine (GRIFFIN, 1984), Loblolly pine (AsKEw, 1988), Scots pine (JONSSON et al., 1976), Douglas-fir (EL-KASSABY et al., 1984) and Black pine (MATZIRIS, 1994). Average flowering synchronizations of the Chinese pine as female parents were positively correlated between most years, except for some special years. Correlation coefficients between male and female flowering synchronizations were negative in most years, even reached the point of statistical significance. This indicated that flowering phenology was under stronger genetic control in the female flowering process than that of males. The broad sense heritability values also proved this conclusion with mean of heritability value in female flowering and male flowering are 0.83 and 0.72 , respectively. From point of genetics, average of flowering synchronization can be a reliable reference to be used for early and late estimation at stage of from initial seed harvest to stable seed production in Chinese pine seed orchard.

Self-pollination was also an important factor affecting genetic diversity and genetic gain in seed orchards. High rates of self-pollination were very common in most of coniferous seed orchards. In this study, most clones in the Chinese pine seed orchard had a higher rate of selfpollination as indicated by the index of flowering synchronization than its average index as male or female parent. It showed the possibility of self-pollination in this first generation clonal seed orchard. Seed orchards with large numbers of clones will more than likely have sufficient pollen mixtures through the pollination period to minimize the rate of self-pollination. As the generations advance, the size of orchards decreases and results 
in greater possibility of self-pollination. Methods should be considered to dilute this effect, such as increasing the number of ramets per clone, when advanced seed orchards are established.

Low synchronization levels in flowering can lead to nonrandom cross-fertilization, reduce genetic diversity and biological adaptability in seed crops, increase the extent of pollution of non-improved pollens from outside orchards and then reduce the genetic gain of the seed lots from the seed orchard (EL-KASSABY and RITLAND, 1986; BLUSH et al., 1993). Studies in floral phenological synchronization in a seed orchard can help to evaluate levels of effective out-crossing and conditions of genetic diversity in seed lots, increase understanding of rates of self-pollination and analyze the levels of flowering synchronization with clones as male parent and female parents, respectively. Therefore, this type of research is essential for making decisions for orchard roguing, supplemental mass pollination or control pollination within an orchard. Based on this type of information, further evaluations can be estimated for gametic contribution and genetic contribution to the seed lots of the seed orchard. Information of flowering synchronization is very important for further genetic improvement of seed orchards. Clones can be clustered by their floral synchronization levels for which clones with both high breeding value and flowering synchronization can be selected for advanced generation seed orchard establishment. Alternatively, clones with low flowering synchronization could be selected as roguing victim for seed orchard management.

\section{Conclusion}

We can conclude that there were significant variations among clones and mating pairs in terms of male and female flowering synchronization in the first generation clonal seed orchard of Chinese pine from stage of initial seed harvest to stable seed production. With increasing age, levels of flowering synchronizations among clones were also likely to rise. Clonal flowering synchronizations indicated some relative stability when clones severed as male or female parents in the seed orchard. In general, average levels of flowering synchronization of male parents were higher than that of female parents. Average flowering synchronizations of female parents were positively correlated among most of the years from initial seed harvest to stable seed production and it can be a reliable reference to be used for early and late estimation in Chinese pine seed orchards. All the clones in clonal seed orchard can be divided into different groups according to their levels of flowering synchronization and can be used as basic information in seed orchard management and advanced future seed orchard establishment.

\section{Acknowledgements}

We are grateful to Prof. YousRy A. EL-KASsABy (University of British Columbia, Faculty of Forestry) for his valuable comments, suggestions and reviews during the preparation of this manuscript.

\section{Funding}

This work was supported by grants from The Fundamental Research Funds for the Central Universities (No.JD2010-4) and Special Fund for Forestry Scientific Research in the Public Interest (No. 201104022).

\section{Literature}

Alizoti, P. G., K. Kilimis and P. Gallions (2010): Temporal and spatial variation of flowering among Pinus nigra Arn. clones under changing climatic conditions. Forest Ecology and Management 259: 786-797.

Askew, G. R. (1985): Quantifying uniformity of gamete production in seed orchard. Silvae Genetica 34 (4-5): 186-188.

Askew, G. R. (1988): Estimation of gamete pool compositions in clonal seed orchards. Silvae Genetica 37 (5-6): 227-232.

Askew, G. R. and D. BLUSH (1990): Short note: an index of phenological overlap in flowering for clonal conifer seed orchards. Silvae Genetica 39 (3-4): 168-171.

Bhumibhamon, S. (1978): Studies on Scots pine seed orchards in Finland with special emphasis on the genetic composition of the seed. Commun. Inst. For. Fenn. 94 (4): 1-118.

Blush, T. D., D. L. BRamletT and Y. A. El-Kassaby (1993): Reproductive phenology of seed orchards. In: Advances in Pollen Management (D. L. BRAmlett, G. R. Askew, T. D. Blush, F. E. BRIDGwater, J. B. JETt, eds.), USDA Agriculture Handbook 698, Washington DC, USA. 15-23.

Boes, T. K., J. R. BRANDlE and W. R. LovetT (1991): Characterization of flowering phenology and seed yield in a Pinus sylvestris clonal seed orchard in Nebraska. Canadian Journal of Forest Research 21: 1721-1729.

BurczyK, J. and W. ChAlupka (1997): Flowering and cone production variability and its effect on parental balance in a Scots pine clonal seed orchard. Annals of Forest Science 54 (2): 129-144.

Chen, X. Y., X. H. Shen, P. YAng, Q. M. PAn and W. G. LI (1995): A study on characteristics of reproductive phenology of Chinese fir seed orchard. Journal of Beijing Forestry University 17 (1): 10-18.

Codesido, V. and E. MERLO (2001): Caracterización fenológica del huerto semillero de Pinus radiata de Sergude. III Congreso Forestal Español. Actas del Congreso. Tomo III: $69-74$.

Codesido, V., E. Merlo and J. Fernández-López (2005): Variation in reproductive phenology in a Pinus radiata D. Don seed orchard in Northern Spain. Silvae Genetica 54 (4-5): 246-256.

Copes, D. L. and R. A. Sniezko (1991): The influence of floral bud phenology on the potential mating system of a wind-pollinated Douglas-fir orchard. Canadian Journal of Forest Research 21: 813-820.

DANUSEviciUs, J. (1987): Flowering and seed production of clones and their stimulation in seed orchards. Forest Ecology and Management 19: 233-240.

EL-Kassaby, Y. A. and K. RitLAND (1986): The relationship of outcrossing rate to reproductive phenology and supplemental mass pollination in a Douglas-fir seed Orchard. Silvae Genetica 35: 240-244.

El-KASSABY, Y. A. and S. REYNOLDS (1990): Reproductive phenology, parental balance and supplemental mass pollination in a Sitka spruce seed orchard. Forest Ecology and Management 31: 45-54. 